\section{LAUNCHPAD RELAUNCHES AS BDJ STUDENT}

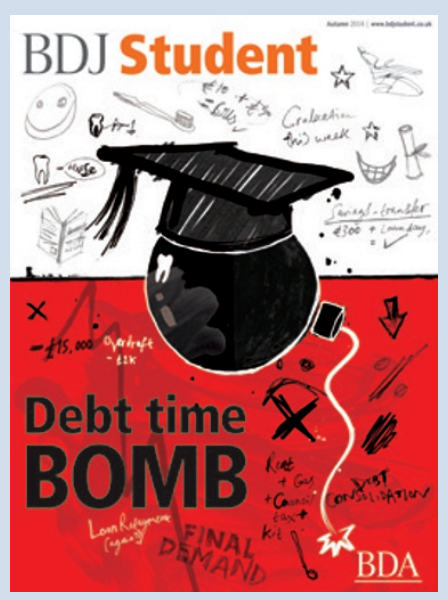

The British Dental Association's (BDA's) magazine for dental students, Launchpad, has relaunched this autumn as BDJ Student.

After months of planning and preparation, the first issue is being published this September. Its new name strengthens the $B D J$ brand, which includes flagship title the $B D J$ and $B D J$ Team - an online magazine for the dental team launched in March 2014.

As well as the new name, the successor to Launchpad, which was originally launched in the 1990s, has a new look and a wider range of content. The Clinical section brings students the latest research and revision questions to test their knowledge, as well as 'how to' guides. The Professional section provides detailed career profiles of inspirational people in the profession; and an expanded version of the popular ethical dilemma feature from Launchpad. The Briefing section highlights the best bits from fellow publications the BDJ, BDA News and BDJ Team.

$B D J$ Student's Editor, Julie Ferry, has edited Launchpad since 2001. In her first BDJ Student editorial Julie says: 'We hope you'll agree that $B D J$ Student is the perfect accompaniment to your dental education:

$B D J$ Student is available to all student and first year graduate members of the BDA and is available online at www.bdjstudent.co.uk. For information on BDA student membership please visit www.bda.org/studentjoin.

FEATURE

\title{
WHAT HAS CHANGED?
}

\author{
Laura Pacey meets two dentists who graduated almost 50 years apart. \\ They discuss their view of the profession, as it was and as it is now.
}

Anton Healy, 1964 graduate Anton Healy celebrated 50 years as a qualified dentist on 22 July 2014 and is triply qualified as a dentist, doctor and pharmacist.

For the past 20 years Anton has worked solely as a general dental practitioner. He reflects on how things were at the start of his career.

My path to dentistry was not direct. I qualified in medicine first at University College Dublin. Having decided that I liked pathology and that there were openings in dental pathology, I then took dentistry at the Royal College of Surgeons Dublin. When I qualified I was quite surprised how enjoyable it was interacting with the dental patients that I was treating in Warrington, quite different to the interaction with medical patients.

After three months I returned to university to study pathology, but after a while I found the isolation of the laboratory was not for me. I returned to the UK and worked as a general medical practitioner. I then established my dental practice in Bebington. Business was slow at first so I worked as a dentist in the afternoons and did medical locum work in the mornings. I had opportunities for further studies but I felt that general practice dentistry suited me fine and left time for golf - a consuming passion of mine.

When I first started a large majority of patients avoided visiting a dentist until the emergency of pain occurred. If the guilty tooth could be saved in many cases it took a great deal of persuasion. The belief for many was that dentures were an inevitable and accepted end. Appointment booking was usually carried out by the lady of the house, for herself and all the family.

When a patient had been persuaded that repair was better than extraction, multiple 'repairs' would follow. If no pain was experienced the patient in many cases was converted to conservation. Crowns were a rarity; the dentist had to seek approval from Eastbourne for single replacements. Additionally, the provision of crowns was much more difficult than today. A copper ring had to be prepared once the crown preparation was completed. Then came the tricky part: green stick composition was heated until it could flow; this was then inserted into the ring and placed around the crown preparation until it cooled. An overall alginate impression of the mouth was taken with copper ring in situ, the ring and composition having been 'notched'. The 'notch' was to enable an accurate alignment of the crown. This exercise was also compounded by poorer quality porcelain than is available today. The weakness of the porcelain resulted in frequent fractures not seen now.

Root fillings were not very common and post crowns were supported by pre-formed metal and in some cases screw posts. When rubber base impression arrived we made cast gold posts.

The road to partial/full dentures was not as gradual as now. The norm in neglected mouths was to extract upper and lower posterior teeth, allow a three month healing period and then do F/F replacement, providing immediate replacement of upper and lower six anterior teeth. This would be followed with new dentures after six months. In the case of ladies, 'small, white teeth' were preferred

Despite the advances with digital $\mathrm{X}$-rays today, they were still highly valuable half a century ago. The output beam from the machine was wider than in the machines of today. Instead of an OPG I had intensifying plates, which allowed for an accurate image of one half-face at a time, much easier than today with small images. The only difference was that we would have the patient wear a lead apron while having an X-ray.

The advent of fluoride in toothpaste has helped enormously with dental public health. In the past, there were no luxuries like dental hygienists. Team members included just the dental nurse and dentist.

Rebecca Jones, 2012 graduate Rebecca Jones graduated from dentistry a couple of years ago, but also has a BSc in genetics.

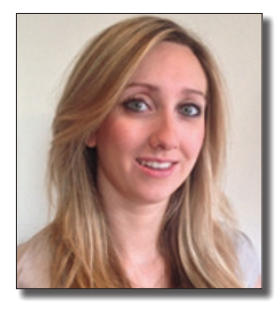

Rebecca has learned that securing a job after qualifiying is not always easy but is excited about the future.

Graduating from Bart's and The London in 2012 and after completing 